\title{
Function of cell-cycle regulators in predicting silent pituitary adenoma progression following surgical resection
}

\author{
SUNG HYUN PARK, JI HWAN JANG, YOUNG MIN LEE, \\ JOON SOO KIM, KYU HONG KIM and YOUNG ZOON KIM \\ Department of Neurosurgery, Samsung Changwon Hospital, \\ Sungkyunkwan University School of Medicine, Changwon, Gyeongnam 51353, Republic of Korea
}

Received May 23, 2016; Accepted July 20, 2017

DOI: 10.3892/ol.2017.7117

\begin{abstract}
The present study investigated the use of cell-cycle regulators for predicting the progression of silent pituitary adenoma (SPA) following surgical resection, via immunohistochemical analysis of tumor samples obtained by surgical resection. The medical records of patients diagnosed with SPA between January 2000 and December 2013 in the Samsung Changwon Hospital, Sungkyunkwan University School of Medicine (Changwon, South Korea) were reviewed. Immunohistochemical staining was performed on sections of the archived, paraffin-embedded tissues obtained by surgery, with all tissues stained for cell-cycle regulatory proteins p16, p15, p21, cyclin-dependent kinase (CDK)4, CDK6, retinoblastoma protein $(\mathrm{pRb})$ and cyclin $\mathrm{D} 1$, as well as E3 ubiquitin-protein ligase mib1 (MIB-1) antigen and p53. The primary end-point was to investigate the expression of cell-cycle regulatory proteins in SPA. The secondary end-point was to estimate the progression-free survival of patients with SPA following surgical resection and to identify its association with the expression of cell-cycle regulatory proteins. Of the 127 SPA samples, 44 (34.6\%) were from patients with progression during a mean follow-up period of 62.4 months (range, 24.2-118.9 months). Immunohistochemical overexpression was identified in 61 samples (48.0\%) for p16, 38 samples (29.9\%) for p15, 19 samples (15.0\%) for p21,49 samples (38.6\%) for CDK4, 17 samples (13.4\%) for CDK6, 57 samples (44.9\%) for $\mathrm{pRb}$ and in 65 samples (51.2\%) for cyclin D1. Multivariate analysis revealed that null cell adenoma [95\% confidence interval (CI), 0.276-0.808], somatotroph SPAs (95\% CI, 1.296-3.121), corticotroph SPAs (95\% CI, 1.811-4.078), pluripotent SPAs (95\% CI, 2.264-5.194), decreased expression of p16 (95\% CI,
\end{abstract}

Correspondence to: Professor Young Zoon Kim, Department of Neurosurgery, Samsung Changwon Hospital, Sungkyunkwan University School of Medicine, 158 Paryong-ro, Masan Hoewon, Changwon, Gyeongnam 51353, Republic of Korea

E-mail: yzkim@skku.edu

Key words: pituitary adenoma, cell cycle, recurrence, immunohistochemistry, progression, prognosis
2.724-5.588), overexpression of $\mathrm{pRb}(95 \% \mathrm{CI}, 2.557-5.333)$, cyclin D1 (95\% CI, 1.894-4.122) and MIB-1 (95\% CI, 1.561-4.133), increased mitotic index (95\% CI, 1.228-4.079), increased p53 expression (95\% CI, 1.307-4.065) and invasion into the cavernous sinus (95\% CI, 3.842-7.502) predicted SPA progression following resection. The results of the present study suggested that specific cell-cycle regulators, including p16, cyclin D1 and pRb, were associated with SPA progression.

\section{Introduction}

Pituitary adenomas (PAs) are typically benign and slow-growing tumors that arise in and consist of adenohypophysial cells (1). PAs are the third most common type of neoplasm in the central nervous system, the most common type of lesion in the sellar region, and represent between 10 and $15 \%$ of intracranial tumors (1). Depending on the hormonal secretion of PAs, they are classified as functioning or non-functioning (silent) (2). Silent PAs (SPAs) can either lack secretion of a sufficient level of hormonal product to increase the serum concentration (totally silent), or can secrete hormonal products that do not cause clinical symptoms or signs that are usual for that hormone (clinically silent) (2). In a cross-sectional study of the inhabitants of Banbury (UK), the prevalence of SPA was 77.6 cases per 100,000 individuals and of these, $28 \%$ exhibited totally silent adenomas (3). In a retrospective study of a Finnish population covering 16 years, $37 \%$ of 164 new cases of PA were classified as SPA, which is equivalent to an incidence rate of $\sim 3$ novel clinical SPAs per 100,000 individuals over 2 years (4). Therapeutic strategies for SPAs vary according to the neurological symptoms and the clinical manifestations caused by excessive adenohypophysial hormone (5). Observation without treatment may be an option for patients without neurological symptoms. Transsphenoidal surgery is the only treatment with a high likelihood of rapidly alleviating symptoms. Radiation therapy may be used to prevent regrowth of residual adenomas following resection (5). Finally, pharmacological treatment is available for a number of subtypes of SPA, including dopamine agonists for lactotroph adenomas and somatostatin analogs for somatotroph adenomas (5).

The totally silent subgroup of PAs exhibits biological behaviors that are different from the clinically silent 
subgroup (6). Null cell adenomas and oncocytomas are assumed to be slow-growing tumors, whereas a number of clinical SPAs, particularly silent corticotroph adenomas and somatotroph adenomas, grow more rapidly, are more prone to be associated with apoplexy or invasiveness and exhibit a higher recurrence rate (7-11). Thus, the application of a reasonably established therapeutic strategy may occur if the surgical specimens are predictive of recurrence. Due to this fact, previous studies have investigated the histological indices of proliferative potential in resected tumors, including bromodeoxyuridine, proliferating cell nuclear antigen and $\mathrm{Ki}-67$ cell cycle-specific nuclear antigen, to determine the association between histological invasiveness and PA recurrence (12-15). According to a previous analysis of human PAs, there are two major molecular alterations to cell cycle regulation during pituitary tumorigenesis; one is the disruption of cyclin-dependent kinase (CDK) regulation and CDK inhibition suppression (16), another is derived from damage to the retinoblastoma protein (pRb) signaling pathway (17). In spite of the effect of cell-cycle deregulation during pituitary tumorigenesis, the prognostic significance of alterations in the expression of cell-cycle regulators remains unknown in SPAs.

In the present study, the immunohistochemical expression of cell-cycle regulators (CDK4, CDK6, p16, p15, p21 and cyclin D1) and the $\mathrm{pRb}$ signaling pathway was investigated in SPA samples to determine the prognostic value for SPA progression following surgical resection. In addition, factors associated with progression-free survival in patients with SPA were characterized.

\section{Patients and methods}

Patients. The present study protocol was approved by the Institutional Review Board of Samsung Changwon Hospital (Changwon, South Korea), and all patients or families provided written informed consent. A retrospective case study and clinical review was conducted of 312 PAs treated surgically between January 2000 and December 2013. All patients underwent surgery and a tumor sample was obtained for diagnosis. Inclusion criteria were: i) No clinical manifestation of excessive pituitary hormone; and ii) serum pituitary hormone $<1.5$ times the upper normal limit [ $8 \mathrm{ng} / \mathrm{ml}$ for growth hormone $(\mathrm{GH}) ; 23.0 \mathrm{ng} / \mathrm{ml}$ for prolactin (PRL), $21 \mathrm{mIU} / \mathrm{ml}$ for follicle-stimulating hormone (FSH), $95 \mathrm{mIU} / \mathrm{ml}$ for luteinizing hormone (LH), $4.2 \mu \mathrm{IU} / \mathrm{ml}$ in thyroid-stimulating hormone (TSH) and $60 \mathrm{pg} / \mathrm{ml}$ for adrenocorticotropic hormone (ACTH)]. Patients undergoing or with a history of medical treatment for functioning PA, including dopamine agonist or somatostatin treatment, were excluded from the present study. Surgical indications were as follows: i) Presence of focal neurological symptoms, including visual field defect and extraocular muscle palsy; ii) altered mentation due to pituitary apoplexy; iii) tumor expansion causing headache and/or hydrocephalus; and iv) patient's requirement to relieve a fear of possessing a growing tumor, even one with a small size.

Biochemical analysis was performed for serum adenohypophysial hormones and pituitary function assessed by basal and dynamic testing. According to the protocol of our institute (18), preoperative serum concentrations of ACTH, TSH, LH, FSH, GH, PRL, cortisol, free T4, estradiol and testosterone were measured. Due to the lack of clinical markers associated with hormonal hypersecretion of ACTH or GH (e.g., hypercortisolism and acromegalic features), screening and dynamic diagnostic tests for Cushing's syndrome or acromegaly were not performed. Preoperative evaluations of adrenal function, including insulin tolerance tests (ITT) and rapid ACTH stimulation test, were not routinely performed as perioperative glucocorticosteroid replacement was routinely conducted during transsphenoidal surgery of pituitary adenomas at Samsung Changwon Hospital. Postoperative evaluations of pituitary function, such as thyroid function tests, and determinations of $\mathrm{LH}, \mathrm{FSH}$, estradiol and testosterone concentrations were conducted in all patients. Tests for the evaluation of postoperative adrenal insufficiency (e.g., ITT or rapid ACTH stimulation tests) were performed for all the patients who exhibited decreased levels of ACTH or cortisol compared to the preoperative results.

Central hypothyroidism was defined as a low free T4 level in the presence of an inappropriate TSH level. Central hypogonadism was diagnosed in the presence of a low estradiol or testosterone level and an inappropriately normal or low gonadotrophin level. Concomitant hyperprolactinemia was defined as a PRL level above the normal range and not consistent with the diagnosis of PRL-secreting adenoma. Hormone values were interpreted according to the normal ranges observed in our laboratory. Postoperative serum pituitary hormone level was regularly checked at every 6 month at least 2 years.

Neuroradiological results of SPAs. SPAs were categorized using the Knosp classification, which determines parasellar growth of SPAs on the basis of coronal sections of preand gadolinium-enhanced magnetic resonance imaging (MRI) (19). Knosp grade 0-I lesions were enclosed adenomas and Knosp grade II-IV lesions were invasive adenoma (19).

All patients underwent preoperative dynamic sellar MRI. Postoperative sellar MRI was performed immediately after surgery to evaluate any residual mass, and the again at 3-month or 6-month intervals within the first 2 years. If tumor-related symptoms were suspected or hormonal alterations developed, sellar MRI was performed immediately. Surgical extent [gross total resection (GTR) and subtotal resection (STR)] was estimated using intraoperative results and by the immediate postoperative MRI, typically within $72 \mathrm{~h}$ after surgery.

Tumor progression was defined as the development of a new tumor in patients with a completely resected tumor or evidence of a new growth of an incompletely resected tumor on serial postoperative MRI. Radiological reviews were conducted by two independent neuroradiologists who were blinded to patient information to classify the SPAs according to the radiological scheme and to determine the tumor progression.

Immunohistochemistry. All SPA specimens were immunohistochemically examined for adenohypophysial hormones [GH (cat. no. NB500-364; dilution 1:1,000; Novus Biologicals, LLC, Littleton, CO, USA), PRL (cat. no. LS-C50522-0.25; dilution 1:500; LifeSpan BioSciences, Inc., Seattle, WA, USA) FSH (cat. no. GTX41060; dilution 1:500; GeneTex, Inc., Irvine, CA, USA), LH (cat. no. LH-101AP; dilution 1:2,000; FabGennix International, Inc., Frisco, TX, USA), TSH (cat. no. LS-C194634-500; dilution 1:200; LifeSpan BioSciences, 
Table I. Results of ROC curve analysis of cell-cycle regulatory proteins and proliferative markers, and determination of the threshold values.

A, Cell cycle regulatory proteins

\begin{tabular}{|c|c|c|c|c|c|}
\hline Protein & $\begin{array}{l}\text { Proportion of IHC } \\
\text { staining nuclei }^{\mathrm{a}}\end{array}$ & $\begin{array}{c}\text { AUC in } \\
\text { ROC curve }\end{array}$ & $\begin{array}{l}\text { Threshold } \\
\text { value, \% }\end{array}$ & Sensitivity, $\%$ & Specificity, \% \\
\hline p16 & $6.43 \pm 3.51$ & 0.62 & 7 & 58.2 & 80.2 \\
\hline $\mathrm{p} 15$ & $9.39 \pm 5.28$ & 0.64 & 10 & 53.1 & 78.3 \\
\hline $\mathrm{p} 21$ & $10.20 \pm 7.28$ & 0.72 & 12 & 62.4 & 70.6 \\
\hline CDK4 & $18.35 \pm 12.29$ & 0.70 & 20 & 66.7 & 79.3 \\
\hline CDK6 & $33.21 \pm 18.08$ & 0.77 & 35 & 73.2 & 75.6 \\
\hline $\mathrm{pRb}$ & $22.43 \pm 13.58$ & 0.72 & 25 & 61.4 & 76.8 \\
\hline Cyclin D1 & $4.52 \pm 3.18$ & 0.78 & 5 & 69.1 & 76.4 \\
\hline
\end{tabular}

$\mathrm{B}$, Proliferative markers

\begin{tabular}{|c|c|c|c|c|c|}
\hline Marker & $\begin{array}{l}\text { Proportion of IHC } \\
\text { staining nuclei }^{\mathrm{a}}\end{array}$ & $\begin{array}{c}\text { AUC in } \\
\text { ROC curve }\end{array}$ & $\begin{array}{l}\text { Threshold } \\
\text { value, \% }\end{array}$ & Sensitivity, $\%$ & Specificity, \% \\
\hline MIB-1 & $1.76 \pm 0.91$ & 0.70 & 2 & 62.1 & 77.0 \\
\hline Mitotic index & $1.67 \pm 0.81$ & 0.75 & 2 & 68.8 & 70.7 \\
\hline p53 & $2.56 \pm 1.32$ & 0.67 & 3 & 64.4 & 67.3 \\
\hline
\end{tabular}

${ }^{a}$ Mean \pm standard deviation. AUC, area under curve; CDK, cyclin-dependent kinase; IHC, immunohistochemical; pRb, retinoblastoma protein; MIB-1, E3 ubiquitin-protein ligase mib1; ROC, receiver operating characteristic.

Inc.) and ACTH (cat. no. GTX89560; dilution 1:50; GeneTex, Inc.)], cell-cycle regulatory proteins (p16, p15, p21, CDK4, CDK6, pRb and cyclin D1) and proliferative markers [E3 ubiquitin-protein ligase mib1 (MIB-1) antigen, mitosis and $\mathrm{p} 53$ ].

Immunohistochemical analysis with a labeled streptavidin-biotin method was performed as described previously by Shim et al (20). Monoclonal or polyclonal primary antibodies against cell cycle regulators and proliferative markers were p16 (cat. no. abx018127; dilution 1:100; Abbexa Ltd., Cambridge, MA, USA), p15 (cat. no. ab53034, dilution 1:100; Abcam, Cambridge, MA, USA), p21 (cat. no. LS-C136937-100; dilution 1:100; LifeSpan BioSciences, Inc.), CDK4 (cat. no. LS-C330939-50; dilution 1:100; LifeSpan BioSciences, Inc.), CDK6 (cat. no. LS-C26471-100; dilution 1:100; LifeSpan BioSciences, Inc.), pRb (cat. no. LS-C51764-50; dilution 1:75; LifeSpan BioSciences, Inc.), cyclin D1 (cat. no. GTX54957; dilution 1:100; GeneTex, Inc.), MIB-1 antigen (cat. no. 43095; dilution 1:100; Signalway Antibody LLC, College Park, MD, USA) and p53 (cat. no. 2526S; dilution 1:100; Cell Signaling Technology, Inc., Danvers, MA, USA). Negative controls omitted the primary antibody and normal pituitary gland sections from autopsy specimens from 3 cadavers were used as positive controls for ACTH, GH, PRL, TSH, LH, FSH, p16, p15, p21, CDK4, CDK6, pRb and cyclin D1. Under high-power magnification (x400), 10 fields were selected in regions with the greatest concentrations of immunopositive nuclei. Each field had between 700 and 1,000 cells, similar to the tumor specimen. Areas of necrosis, normal adenohypophysial cells and endothelial cells were excluded from evaluation.
Immunoreactivity of proteins and markers was determined as a proportion of immunopositive cells from 1,000 cells, determined by manual counting. Mitosis was counted after hematoxylin and eosin staining, and the mitotic index defined as the number of mitotic cells/10 high-power fields. All slides were separately reviewed by two neuropathologists who were blinded to the clinical and radiological information. SPAs were divided into 6 categories according to immunohistochemical staining for adenohypophysial cells: Null cell adenoma, gonadotrophic SPA, somatotrophic SPA, corticotrophic SPA, lactotrophic SPA and pluripotent SPA. This was determined using the protocol of a previous study (5).

Immunoreactivity of cell-cycle regulators and proliferative markers was used to determine whether the markers affected SPA progression. Receiver operating characteristic (ROC) curve analysis was performed using SPSS software version 12.0 (SPSS Inc., Chicago, IL, USA) for immunoreactivity of the cell-cycle regulatory proteins and proliferative markers to predict the likelihood of progression (21). The area under the ROC curve was used to determine the optimal threshold of the mean proportion of immunopositive cells from 1,000 cells. Sensitivity was calculated as the true positive rate (number of true positives divided by the sum of the number of true positives and number of false negatives), specificity as the true negative rate (number of true negatives divided by the sum of the number of true negatives and number of false positives) and accuracy as the sum of the number of true positives and true negatives, divided by the total number of positives and negatives. True positives mean that the immunoreactivity proportion above the threshold value has an influence on the 
long time to progression (TTP), and true negatives mean that the immunoreactivity proportion below the threshold value has an influence on the short TTP. The threshold of immunoreactivity with the greatest sensitivity and specificity was determined, and using sensitivity-specificity analysis, a threshold point at which sensitivity and specificity crossed that associated with recurrence was determined for each marker (Table I). On the basis of the threshold value for immunoreactivity for each protein and marker, sequential association analysis for SPA progression was performed.

Statistical analysis. Differences between subgroups were analyzed using Student's t-test for normally distributed, continuous values and the Mann-Whitney test for abnormally distributed, continuous values. $\chi^{2}$-tests were used to analyze categorical variables. Variables significantly associated with SPA progression by univariate analyses were used in multivariate analyses. In addition, several variables of interest that were associated with tumor progression in the literature were used in multivariate analysis. The impact of variables on progression was evaluated by comparing progression-free survival curves using a log-rank test. In multivariate analysis, the Cox proportional hazard regression model was used to assess the independent effects of specific factors on the progression rate of SPAs and to define hazard ratios (HRs) for significant covariates. $\mathrm{P}<0.05$ was considered to indicate a statistically significant difference. SPSS software version 12.0 (SPSS Inc.) was used for statistical analysis.

\section{Results}

Clinical characteristics of patients with SPAs. According to the review of medical records, during the study period, 312 patients underwent surgical resection for newly diagnosed PAs and 127 $(40.7 \%)$ were diagnosed with SPA. All patients were treated by an endoscopic endonasal trans-sphenoidal approach. The mean patient age was 48.9 years (range, 24.2-85.6 years), with 71 males and 56 females. The most common presenting symptom was headache (35.4\%) (Table II).

Radiographically, the mean maximal diameter of SPAs was $31.5 \mathrm{~mm}$ (range, $8.0-65.5 \mathrm{~mm}$ ); $33.7 \mathrm{~mm}$ (range 10.0-65.5 mm) in patients with focal neurological symptoms, including visual field defect or extraocular muscle palsy, and $29.8 \mathrm{~mm}$ $(8.0-52.3 \mathrm{~mm})$ in those without focal neurological symptoms $(\mathrm{P}=0.458$, Student's t-test). GTR was performed for 82 SPAs $(64.5 \%)$; 35 SPAs $(62.5 \%)$ in patients with focal neurological symptoms and 47 SPAs $(66.2 \%)$ in those without focal neurological symptoms $\left(\mathrm{P}=0.525, \chi^{2}\right.$-test $)$. Therefore, among patients with focal neurological symptoms, 35 patients underwent GTR, and among those without focal neurological symptoms, 24 patients underwent STR $\left(\mathrm{P}=0.172, \chi^{2}\right.$-test $)$. The size of SPA and major clinical features were not significantly influenced by the immunoreactivity of cell cycle regulators (Table III).

No patients underwent adjuvant radiotherapy without evidence of recurrence or regrowth during follow-up. In 45 patients who had residual tumors following subtotal resection, marked improvement of clinical symptoms was observed. During follow-up with regular examination of serum pituitary hormone and clinical symptoms, patients did not experience worsening symptoms or increased serum pituitary hormone.
Table II. Clinical characteristics of patients with silent pituitary adenoma.

\begin{tabular}{lc}
\hline Variable & Value \\
\hline Total patients, $\mathrm{n}$ & 127 \\
Mean age (range), years & $48.9(24.2-85.6)$ \\
Male:female ratio & $71: 56$ \\
Presenting symptom, $\mathrm{n}(\%)$ & \\
Headache & $45(35.4)$ \\
Visual field defect & $43(33.9)$ \\
Extraocular muscle palsy & $13(10.2)$ \\
Altered mentation & $7(5.5)$ \\
None (incidental detection) & $19(15.0)$ \\
Cell type, $\mathrm{n}(\%)$ & \\
Null cell & $29(22.8)$ \\
Gonadotroph & $41(32.3)$ \\
Somatotroph & $19(15.0)$ \\
Corticotroph & $16(12.6)$ \\
Lactotroph & $15(11.8)$ \\
Pluripotent & $7(5.5)$ \\
Knosp classification, $\mathrm{n}(\%)$ & \\
0-I (enclosed adenoma) & $76(59.8)$ \\
II-IV (invasive adenoma) & $51(40.2)$ \\
Mean maximum diameter (range), mm & $31.5(8.0-6.5)$ \\
Extent of surgical resection, $\mathrm{n}(\%)$ & \\
Gross total resection & $82(64.6)$ \\
Subtotal resection & $45(35.4)$ \\
\hline &
\end{tabular}

Immunohistochemical staining. Adenohypophysial cells were immunohistochemically stained, which revealed gonadotrophic cells in 41 samples $(32.2 \%)$, somatotrophic cells in 19 samples (15.0\%), corticotrophic cells in 16 samples (12.6\%), lactotrophic cells in 15 samples and $\geq 2$ adenohypophysial cells in 7 samples $(5.5 \%)$ (Table II).

According to the ROC curve analysis, immunohistochemical overexpression above the threshold value was determined as follows: $7 \%$ in p16, $10 \%$ in p15, $12 \%$ in p21, $20 \%$ in CDK4, $35 \%$ in CDK6, 25\% in pRb, $5 \%$ in cyclin D1, 2\% in MIB-1 and $3 \%$ in $\mathrm{p} 53$. Cell-cycle regulatory protein analysis demonstrated that p16 was immunohistochemically overexpressed above the threshold value in 61 samples $(48.0 \%)$, p15 in 38 samples (29.9\%), p21 in 19 samples $(15.0 \%)$, CDK4 in 49 samples (38.6\%), CDK6 in 17 samples (13.4\%), pRb in 57 samples (44.9\%) and cyclin D1 in 65 samples (51.2\%) (Fig. 1). Immunohistochemical overexpression of the proliferative marker MIB-1 was identified in 54 samples (42.5\%), mitotic index increased in 51 samples (40.2\%) and immunohistochemical overexpression of p53 was observed in 39 samples $(30.7 \%)$. Additionally, there was no statistical difference in the immunoreactivity for cell cycle regulators and proliferative markers according to the cell types (Table IV).

Progression of SPAs following surgery. All patients were followed for $\geq 24$ months and the mean follow-up duration was 60.9 months (range, 25.3-137.4 months). During follow-up, 
Table III. Size of silent pituitary adenomas and the presence of focal neurological symptoms, including visual field defects and extraocular muscle palsy, according to the results of immunohistochemical staining for cell-cycle regulators.

\begin{tabular}{|c|c|c|c|c|c|}
\hline Protein & IHC staining & $\begin{array}{c}\text { Mean maximal } \\
\text { diameter }( \pm \mathrm{SD}), \mathrm{mm}\end{array}$ & P-value ${ }^{a}$ & $\begin{array}{l}\text { Patients with focal } \\
\text { neurological } \\
\text { symptoms, n }(\%)\end{array}$ & P-value ${ }^{b}$ \\
\hline \multirow[t]{2}{*}{ p16 } & Overexpression & $28.9( \pm 10.2)$ & 0.162 & $25(41.0)$ & 0.118 \\
\hline & Decreased expression & $33.9( \pm 11.0)$ & & $31(47.0)$ & \\
\hline \multirow[t]{2}{*}{$\mathrm{p} 15$} & Overexpression & $30.7( \pm 9.8)$ & 0.758 & $16(42.1)$ & 0.843 \\
\hline & Decreased expression & $31.8( \pm 10.5)$ & & $40(44.9)$ & \\
\hline \multirow[t]{2}{*}{ p21 } & Overexpression & $28.4( \pm 8.7)$ & 0.097 & $9(47.4)$ & 0.251 \\
\hline & Decreased expression & $32.0( \pm 10.3)$ & & $47(43.5)$ & \\
\hline \multirow[t]{2}{*}{ CDK4 } & Overexpression & $33.8( \pm 11.5)$ & 0.254 & $22(44.9)$ & 0.913 \\
\hline & Decreased expression & $30.1( \pm 8.8)$ & & $34(43.6)$ & \\
\hline \multirow[t]{2}{*}{ CDK6 } & Overexpression & $32.6( \pm 9.6)$ & 0.682 & $7(41.2)$ & 0.681 \\
\hline & Decreased expression & $31.3( \pm 7.9)$ & & $49(44.5)$ & \\
\hline \multirow[t]{2}{*}{$\mathrm{pRb}$} & Overexpression & $33.4( \pm 10.4)$ & 0.206 & $27(47.4)$ & 0.104 \\
\hline & Decreased expression & $30.0( \pm 11.2)$ & & $29(41.4)$ & \\
\hline \multirow[t]{2}{*}{ Cyclin D1 } & Overexpression & $32.2( \pm 12.1)$ & 0.341 & $30(46.2)$ & 0.237 \\
\hline & Decreased expression & $30.8( \pm 9.6)$ & & $26(41.9)$ & \\
\hline
\end{tabular}

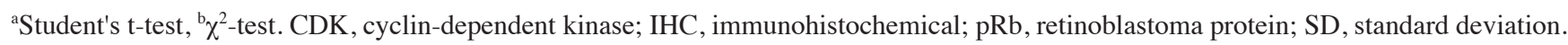
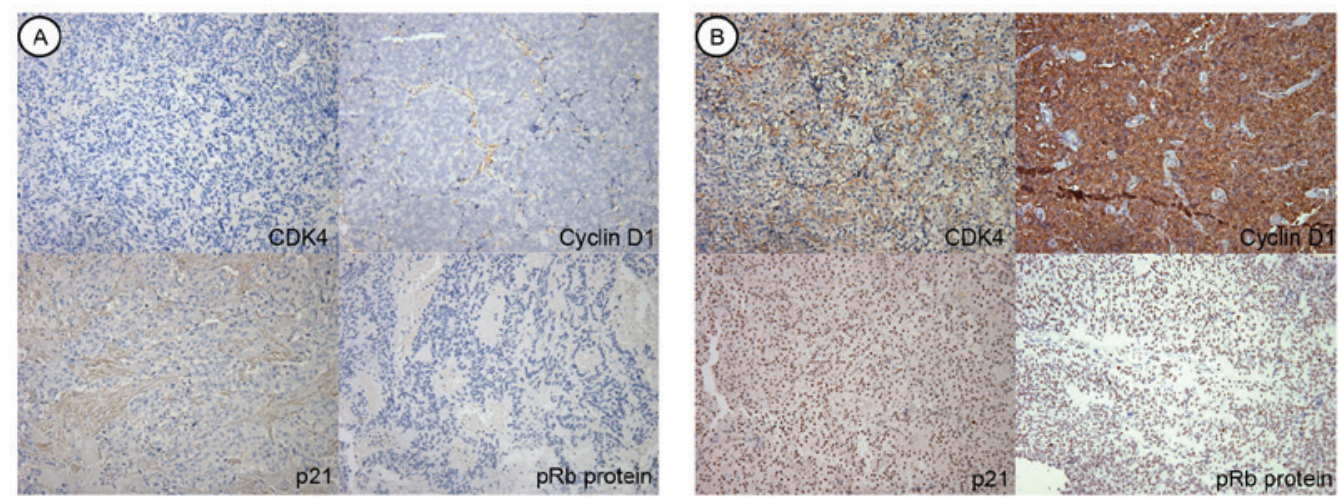

Figure 1. Results of immunohistochemical staining for cell cycle regulatory proteins (magnification, x10). (A) immunohistochemical understaining of CDK4 $(<20 \%)$, cyclin D1 (<5\%), p21 (<12\%) and pRb (<25\%). (B) Immunohistochemical overstaining of CDK4 ( $\geq 20 \%)$, cyclin D1 $(\geq 5 \%)$, p21 $(\geq 12 \%)$ and pRb $(\geq 25 \%)$. $\mathrm{CDK}$, cyclin-dependent kinase; $\mathrm{pRb}$, retinoblastoma protein.

44 patients (34.6\%) experienced progression following surgical resection and the mean TTP following surgery was 36.6 months (range, 5.6-89.4 months). By cell type, progression occurred for 6/29 (20.7\%) null cell adenomas, 10/41 (24.4\%) gonadotropic SPAs, 9/19 (47.4\%) somatotrophic SPAs, 8/16 (50.0\%) corticotrophic SPAs, 6/15 (40.0\%) lactotrophic SPAs and 5/7 (71.4\%) pluripotent SPAs.

Immunohistochemical overexpression and decreased staining are associated with mean TPP. In the cell-cycle regulatory proteins, the mean TTP was increased in patients with immunohistochemical overexpression compared with that in patients with decreased expression $(\mathrm{P}=0.002)$. The mean TTP was also shorter in patients with immunohistochemical overexpression, compared with those with decreased expression, for $\mathrm{pRb}(\mathrm{P}=0.009)$ and cyclin $\mathrm{D} 1(\mathrm{P}=0.028)$ (Table V). In the proliferative markers, the mean TTP was decreased in patients with immunohistochemical overexpression, compared with those with immunohistochemically decreased expression, for MIB-1 antigen $(\mathrm{P}=0.014)$, mitotic index $(\mathrm{P}=0.031)$ and $\mathrm{p} 53$ $(\mathrm{P}=0.047$; Table V).

Univariate analysis of predisposing factors for SPA progression. Univariate analysis revealed that progression occurred significantly more often with somatotrophic SPAs $(\mathrm{P}=0.040)$, corticotrophic SPAs $(\mathrm{P}=0.013)$ and pluripotent SPAs $(\mathrm{P}<0.001)$ compared with null cell adenomas (Table VI). In terms of cell-cycle regulatory proteins, patients with SPA samples that were immunohistochemically overexpressed for p16 exhibited significantly decreased progression rates compared with patients with decreased expression $(\mathrm{P}<0.001)$. In addition, patients with SPA samples that were 
Table IV. Distribution of immunohistochemically overexpressed cell cycle regulators and proliferative markers in silent pituitary adenomas according to the cell types $(n=127)$.

A, Cell cycle regulators

\begin{tabular}{|c|c|c|c|c|c|c|c|}
\hline Protein & $\begin{array}{c}\text { Null cell } \\
\text { adenoma } \\
(n=29)\end{array}$ & $\begin{array}{l}\text { Gonadotroph } \\
\text { adenoma } \\
(n=41)\end{array}$ & $\begin{array}{l}\text { Somatotroph } \\
\text { adenoma } \\
(n=19)\end{array}$ & $\begin{array}{l}\text { Corticotroph } \\
\text { adenoma } \\
(n=16)\end{array}$ & $\begin{array}{l}\text { Lactotroph } \\
\text { adenoma } \\
(n=15)\end{array}$ & $\begin{array}{l}\text { Pluripotent } \\
\text { adenoma } \\
(\mathrm{n}=7)\end{array}$ & P-value \\
\hline p16 & $15(51.7)$ & $20(48.8)$ & $9(47.4)$ & $7(43.8)$ & $7(46.7)$ & $3(42.9)$ & 0.816 \\
\hline p15 & $10(34.5)$ & $12(29.3)$ & $5(26.3)$ & $4(25.0)$ & $5(33.3)$ & $2(28.6)$ & 0.774 \\
\hline $\mathrm{p} 21$ & $5(17.2)$ & $6(14.6)$ & $2(10.5)$ & $2(12.5)$ & $3(20.0)$ & $1(14.3)$ & 0.635 \\
\hline CDK4 & $11(37.9)$ & $16(39.0)$ & $8(42.1)$ & $6(37.5)$ & $5(33.3)$ & $3(42.9)$ & 0.592 \\
\hline CDK6 & $4(13.8)$ & $5(12.3)$ & $3(15.8)$ & $2(12.5)$ & $2(13.3)$ & $1(14.3)$ & 0.872 \\
\hline $\mathrm{pRb}$ & $12(41.4)$ & $18(43.9)$ & $9(47.4)$ & $8(50.0)$ & $7(46.7)$ & $3(42.9)$ & 0.526 \\
\hline Cyclin D1 & $15(51.7)$ & $21(51.2)$ & $10(52.6)$ & $9(56.3)$ & $7(46.7)$ & $3(42.9)$ & 0.603 \\
\hline
\end{tabular}

B, Proliferative markers

\begin{tabular}{|c|c|c|c|c|c|c|c|}
\hline Protein & $\begin{array}{l}\text { Null cell } \\
\text { adenoma } \\
(n=29)\end{array}$ & $\begin{array}{l}\text { Gonadotroph } \\
\text { adenoma } \\
(n=41)\end{array}$ & $\begin{array}{l}\text { Somatotroph } \\
\text { adenoma } \\
(n=19)\end{array}$ & $\begin{array}{l}\text { Corticotroph } \\
\text { adenoma } \\
(\mathrm{n}=16)\end{array}$ & $\begin{array}{l}\text { Lactotroph } \\
\text { adenoma } \\
\quad(n=15)\end{array}$ & $\begin{array}{c}\text { Pluripotent } \\
\text { adenoma } \\
(n=7)\end{array}$ & P-value \\
\hline MIB-1 & $11(37.9)$ & $16(39.0)$ & $10(52.6)$ & $9(56.3)$ & $5(33.3)$ & $3(42.9)$ & 0.087 \\
\hline Mitotic index & $10(34.5)$ & $15(36.6)$ & $10(52.6)$ & $8(50.0)$ & $6(40.0)$ & $2(28.6)$ & 0.069 \\
\hline p53 & $7(24.1)$ & $12(29.3)$ & $7(36.8)$ & $6(37.5)$ & $5(33.3)$ & $2(28.6)$ & 0.381 \\
\hline
\end{tabular}

${ }^{\mathrm{a}} \chi^{2}$ test. CDK, cyclin-dependent kinase; pRb, retinoblastoma protein; MIB-1, E3 ubiquitin-protein ligase mib1.

immunohistochemically overexpressed for $\mathrm{pRb}(\mathrm{P}=0.008)$ and cyclin $\mathrm{D} 1 \quad(\mathrm{P}=0.038)$ exhibited significantly increased progression rates compared with that for patients with immunohistochemically decreased expression. Patients with SPA samples that were immunohistochemically overexpressed for proliferative markers exhibited significantly increased progression rates compared with those for patients with immunohistochemically decreased expression; MIB-1 $(\mathrm{P}=0.010)$, mitotic index $(\mathrm{P}=0.026)$ and p53 $(\mathrm{P}=0.037$; Table VI).

Regarding radiological factors, patients with invasive SPAs exhibited an increased progression rate compared with that of patients with enclosed SPAs $(\mathrm{P}<0.001)$. Furthermore, patients with SPAs $\geq 25 \mathrm{~mm}$ exhibited an increased progression rate compared with that of patients with SPAs $<25 \mathrm{~mm}(\mathrm{P}=0.042)$. The extent of surgical resection for SPA was not associated with progression rate $(\mathrm{P}=0.683)$.

Multivariate analysis of predisposing factors for SPA progression. Multivariate analysis using the Cox proportional hazard regression model for SPA progression following surgical resection demonstrated that factors independently associated with progression were null cell adenoma [hazard ratio (HR), 0.553; 95\% confidence interval (CI), 0.266-0.841], somatotrophic SPAs (HR, 2.197; 95\% CI, 1.298-3.096), corticotrophic SPAs (HR, 2.951; 95\% CI, 1.820-4.082), pluripotent SPAs (HR, 3.694; 95\% CI, 2.227-5.161), SPA samples with immunohistochemically decreased expression for p16 (HR, 4.170; 95\% CI, 2.812-5.522), SPA samples overexpressing pRb (HR, 3.918; 95\% CI, 2.532-5.304), SPA samples overexpressing cyclin D1 (HR, 3.022; 95\% CI, 1.898-4.146), SPA samples overexpressing MIB-1 (HR, 2.835; 95\% CI, 1.549-4.121), SPA samples overexpressing p53 (HR, 2.484; 95\% CI, 1.267-3.701), increased mitotic index (HR, 2.673; 95\% CI, 1.235-4.111) and Knosp grades II-IV (HR, 5.677; 95\% CI, 3.840-7.514) (Table VII). The Kaplan-Meier survival curve analysis and log-rank test revealed the same results (Fig. 2).

\section{Discussion}

The present study had a similar proportion of SPAs to PAs and surgical outcome as previous studies $(2,5)$. The composition of SPA subtypes (null cell adenoma, and gonadotroph, lactotroph, somatotroph, corticotroph and pluripotent SPAs) was similar to other studies $(2,5)$. Categorizing SPAs into clinical and true SPAs is controversial; in the present study, SPAs were defined according to the description by Mayson and Snyder $(2,5)$. In the systemic review and meta-analysis in 2012 by Chen et al (22), the rate of STR was between 21.4 and $79.4 \%$ following transsphenoidal surgery of SPA, and between 12 and $46 \%$ of patients with SPA exhibited tumor regrowth between 42 and 112 months after surgery. The surgical outcomes demonstrated by Chen et al (22) were similar compared with the results of the present study.

According to a previous study, the primary treatment of SPA is surgical resection focused on relieving the mass effect, restoring pituitary function and validating a tissue diagnosis (23). As the majority of the SPAs are macroadenoma at diagnosis, the traditional indication of surgery for SPA is the tumor expansion associated with focal neurological symptoms. 
Table V. Time to progression and progression rate according to the result of immunohistochemical staining for the cell-cycle regulators and proliferative markers, and cell types.

A, Cell cycle regulators

\begin{tabular}{|c|c|c|c|c|c|c|}
\hline \multirow[b]{2}{*}{ Protein } & \multirow[b]{2}{*}{ Threshold value, $\%$} & \multicolumn{2}{|c|}{$\begin{array}{c}\text { Sample with } \\
\text { immunohistochemical } \\
\text { overexpression }\end{array}$} & \multicolumn{2}{|c|}{$\begin{array}{c}\text { Sample with } \\
\text { immunohistochemically } \\
\text { decreased expression }\end{array}$} & \multirow[b]{2}{*}{ P-value } \\
\hline & & Progression, n (\%) & TTP, months ${ }^{\mathrm{a}}$ & Progression, n (\%) & TTP, months ${ }^{\mathrm{a}}$ & \\
\hline p16 & 7 & $11 / 61(18.0)$ & $43.7 \pm 17.2$ & $33 / 66(50.0)$ & $31.3 \pm 14.0$ & $0.002^{\mathrm{b}}$ \\
\hline p15 & 10 & $11 / 38(28.9)$ & $38.2 \pm 6.8$ & 33/89 (37.1) & $32.8 \pm 15.3$ & 0.337 \\
\hline $\mathrm{p} 21$ & 12 & $7 / 19(36.8)$ & $37.9 \pm 14.5$ & $37 / 108(34.3)$ & $33.4 \pm 15.8$ & 0.795 \\
\hline CDK4 & 20 & $19 / 49(38.8)$ & $35.2 \pm 3.8$ & $25 / 78(32.1)$ & $37.3 \pm 15.0$ & 0.718 \\
\hline CDK6 & 35 & $6 / 17(35.3)$ & $35.5 \pm 14.7$ & $38 / 110(34.5)$ & $37.0 \pm 13.8$ & 0.854 \\
\hline $\mathrm{pRb}$ & 25 & $29 / 57(50.9)$ & $31.3 \pm 12.6$ & $15 / 70(21.4)$ & $43.1 \pm 15.9$ & $0.009^{\mathrm{b}}$ \\
\hline Cyclin D1 & 5 & $28 / 65(43.1)$ & $32.4 \pm 13.5$ & $16 / 62(25.8)$ & $41.2 \pm 16.2$ & $0.028^{\mathrm{b}}$ \\
\hline
\end{tabular}

B, Proliferative markers

\begin{tabular}{|c|c|c|c|c|c|c|}
\hline \multirow[b]{2}{*}{ Protein } & \multirow[b]{2}{*}{ Threshold value, $\%$} & \multicolumn{2}{|c|}{$\begin{array}{c}\text { Sample with } \\
\text { immunohistochemical } \\
\text { overexpression }\end{array}$} & \multicolumn{2}{|c|}{$\begin{array}{c}\text { Sample with } \\
\text { immunohistochemically } \\
\text { decreased expression }\end{array}$} & \multirow[b]{2}{*}{ P-value } \\
\hline & & Progression, n (\%) & TTP, months ${ }^{\mathrm{a}}$ & Progression, n (\%) & TTP, months ${ }^{\mathrm{a}}$ & \\
\hline MIB-1 & 2 & $25 / 54(46.3)$ & $32.2 \pm 12.1$ & $19 / 73(26.0)$ & $41.9 \pm 15.5$ & $0.014^{\mathrm{b}}$ \\
\hline Mitotic index & 2 & $22 / 51(43.1)$ & $33.0 \pm 14.6$ & $22 / 76(28.9)$ & $39.1 \pm 14.3$ & $0.031^{\mathrm{b}}$ \\
\hline p53 & 3 & $16 / 39(41.0)$ & $33.7 \pm 10.2$ & $28 / 88(31.8)$ & $38.8 \pm 15.2$ & $0.047^{\mathrm{b}}$ \\
\hline
\end{tabular}

${ }^{\mathrm{a}}$ Mean \pm standard deviation. ${ }^{\mathrm{b}} \mathrm{P}<0.05$, Mann-Whitney U test. CDK, cyclin-dependent kinase; pRb, retinoblastoma protein; MIB-1, E3 ubiquitin-protein ligase mib1; SD, standard deviation; TTP, time to progression.

Although patients with SPA in the present study underwent surgical resection following the aforementioned indications, the results of surgery for endocrine-inactive adenomas are not as clearly defined as those of surgery for functioning adenomas, as there is no clear criterion for a cure (5).

Expression levels for p16 and pRb in pituitary adenomas were similar to those identified in the study by Kirsch et al (23), which observed positive staining $>25 \%$ for p16 in $57 \%$ of samples and for $\mathrm{pRb}$ in $48 \%$ of pituitary adenomas by immunohistochemical analysis. However, in the present study, the rate of positive immunoreactivity $>25 \%$ was relatively low; for p16 in $13.2 \%$ of SPAs and for pRb in $28.7 \%$ of SPAs. This discrepancy may be due to the following reasons: i) Kirsch's analysis included all types of pituitary adenomas, including functioning and non-functioning pituitary adenomas; ii) there are the variations in the immunohistochemical analysis due to concentration and dilution of antibodies used; and iii) there is inter-observer variation in the subjective interpretations for immunohistochemical analysis.

The present study demonstrated that the cell-cycle regulatory proteins $\mathrm{p} 16, \mathrm{pRb}$ and cyclin $\mathrm{D} 1$, estimated using immunohistochemical staining, were associated with SPA progression following surgical resection. It was identified that $\mathrm{pRb}$ is involved in SPA progression. The prognostic ability of cell-cycle regulatory proteins and proliferative markers has been identified in renal cell carcinoma (24), gallbladder malignancies (17), gastric adenocarcinoma (25) and breast cancer (26). Therefore, if these cell cycle regulators influence the tumor size and the onset of neurological symptoms, the clinical outcome of SPA may be altered. However, the principal clinical features of SPA were not different, according to the status of immunoreactivity of cell cycle regulators, which may explain why there is no effect on tumor progression from the association between cell cycle regulators and clinical features.

In the cell cycle, mitotic stimulation leads cyclin D1 to activate CDK4 and CDK6 during early $\mathrm{G}_{1}$ phase, which partially phosphorylates pRb. Cyclin D1 typically binds to $C D K$ during $G_{1}$ and is required to bypass the cell cycle restriction point into $S$ phase (27), which leads to cell cycle progression and tumor cell proliferation. In addition, $\mathrm{pRb}$ is active and hypophosphorylated in quiescent cells, and inactive and hyperphosphorylated at the $\mathrm{G}_{1}-\mathrm{S}$ transition. Therefore, the level of phosphorylated $\mathrm{pRb}$ indicates cell cycle progression into the S phase (27). Attenuated cyclin D1 and pRb expression in SPA may explain the increased SPA progression observed in the present study. CDK inhibitors, including p16, oppose CDK activation. During early $\mathrm{G}_{1}$ phase, p16 binds to CDK4 and 6, and prevents cyclin D activation (27). Thus, increased expression 
Table VI. Univariate analysis of factors predicting progression of silent pituitary adenomas $(\mathrm{n}=127)$.

\begin{tabular}{|c|c|c|c|c|}
\hline Factor & Progression rate, $\%$ & HR & $95 \% \mathrm{CI}$ & P-value \\
\hline Age & - & 1.318 & $0.898-1.738$ & 0.714 \\
\hline \multicolumn{5}{|l|}{ Cell type } \\
\hline Null cell & 20.7 & 1.000 & & \\
\hline Gonadotroph adenoma & 24.4 & 1.155 & $0.564-1.647$ & 0.853 \\
\hline Somatotroph adenoma & 47.4 & 4.372 & $2.325-6.419$ & $0.040^{\mathrm{a}}$ \\
\hline Corticotroph adenoma & 50.0 & 4.876 & $2.517-7.235$ & $0.013^{\mathrm{a}}$ \\
\hline Lactotroph adenoma & 40.0 & 2.174 & $0.958-3.336$ & 0.052 \\
\hline Pluripotent adenoma & 71.4 & 8.676 & $5.083-12.269$ & $<0.001^{\mathrm{b}}$ \\
\hline \multicolumn{5}{|c|}{$\begin{array}{l}\text { Immunohistochemical overexpression } \\
\text { of cell-cycle regulator }\end{array}$} \\
\hline p16 & 18.0 & 0.314 & $0.109-0.519$ & $<0.001^{\mathrm{b}}$ \\
\hline $\mathrm{p} 15$ & 28.9 & 0.793 & $0.569-1.017$ & 0.124 \\
\hline $\mathrm{p} 21$ & 36.8 & 1.503 & $0.759-2.247$ & 0.526 \\
\hline CDK4 & 38.8 & 1.732 & $0.785-2.679$ & 0.433 \\
\hline CDK6 & 35.3 & 1.386 & $0.661-2.011$ & 0.802 \\
\hline $\mathrm{pRb}$ & 50.9 & 6.285 & $3.088-9.482$ & $0.008^{\mathrm{a}}$ \\
\hline Cyclin D1 & 43.1 & 4.394 & $1.364-7.424$ & $0.038^{\mathrm{a}}$ \\
\hline \multicolumn{5}{|c|}{$\begin{array}{l}\text { Immunohistochemical overexpression } \\
\text { of proliferative marker }\end{array}$} \\
\hline MIB-1 & 46.3 & 4.249 & $2.518-5.979$ & $0.010^{\mathrm{a}}$ \\
\hline Mitotic index & 43.1 & 3.782 & $1.843-5.721$ & $0.026^{\mathrm{a}}$ \\
\hline p53 & 41.0 & 3.558 & $1.447-5.669$ & $0.037^{\mathrm{a}}$ \\
\hline \multicolumn{5}{|l|}{ Knosp classification } \\
\hline $0-\mathrm{I}$ & 21.1 & 1.000 & & \\
\hline II-IV & 54.9 & 8.840 & $4.882-12.798$ & $<0.001^{\mathrm{b}}$ \\
\hline Maximal diameter of Tumor & - & 2.857 & $1.421-4.293$ & $0.042^{\mathrm{a}}$ \\
\hline \multicolumn{5}{|l|}{ Extent of surgical resection } \\
\hline Gross total resection & 32.9 & 1.000 & & \\
\hline Subtotal resection & 37.8 & 1.358 & $0.790-1.926$ & 0.683 \\
\hline
\end{tabular}

${ }^{\mathrm{a}} \mathrm{P}<0.05,{ }^{\mathrm{b}} \mathrm{P}<0.001$. For immunohistochemically overexpressed cell cycle regulators and proliferative markers, the TTP of an immunohistochemically normally expressed sample was used as the standard. CDK, cyclin-dependent kinase; CI, confidence interval; MIB-1, E3 ubiquitin-protein ligase mib1; pRb, retinoblastoma protein; TTP, time to progression; HR, hazard ratio.

of p16 may prevent proliferation and SPA, which would explain the results of the present study. Although null cell adenomas are assumed to be slow-growing tumors, a number of types of silent adenoma, in particular silent corticotroph adenomas and somatotroph adenomas, grow more rapidly and are more likely to be associated with apoplexy or invasiveness, and to exhibit increased rates of progression $(9,11)$. The results of the present study demonstrated that SPAs that were somatotroph, corticotroph or pluripotent were associated with progression. Cavernous sinus invasion, which is more frequent for SPAs that are somatotroph, corticotroph or pluripotent, makes total resection difficult and may influence progression rates.

The present study had a number of limitations. First, immunohistochemical study is well-known to have different outcomes depending on the different professionals performing the analysis; therefore, this subjective interpretation should be complemented by other objective analyses, including molecular functional study, using several quantitative methods. Secondly, the SPA classification presents limitations. Although SPAs may be separated into true and clinical SPAs, using immunohistochemical and electron-microscope appearance (28), electron microscopic studies were not performed in the present study. Therefore, it cannot be guaranteed that the present study identified definitive classifications of SPA subtypes. Thirdly, not all cell-cycle regulatory proteins were examined. In the present study, a portion of the cell-cycle control system, specifically the $G_{1}$ to $S$ transition, was focused on, which may have biased the interpretation of the results and neglected a number of interactions between regulatory proteins. The fourth concern is that the present study does not reflect modern molecular and biological interpretations of SPAs that are increasing our understanding of the pathobiology of SPAs.

The results of the present study suggested that expression of a number of cell-cycle regulators, including $\mathrm{p} 16, \mathrm{pRb}$ 
Table VII. Multivariate analysis of factors predicting progression of silent pituitary adenomas $(\mathrm{n}=127)$.

\begin{tabular}{|c|c|c|c|}
\hline Factor & HR & $95 \% \mathrm{CI}$ & P-value \\
\hline $\operatorname{Age}^{\mathrm{a}}$ & 1.524 & $0.882-2.166$ & 0.294 \\
\hline Null cell vs. other cell type & 0.553 & $0.266-0.841$ & $0.002^{\mathrm{b}}$ \\
\hline Gonadotroph adenoma vs. other cell type & 0.851 & $0.682-1.021$ & 0.068 \\
\hline Somatotroph adenoma vs. other cell type & 2.197 & $1.298-3.096$ & $0.046^{\mathrm{b}}$ \\
\hline Corticotroph adenoma vs. other cell type & 2.951 & $1.820-4.082$ & $0.023^{\mathrm{b}}$ \\
\hline Lactotroph adenoma vs. other cell type & 1.342 & $0.876-1.808$ & 0.381 \\
\hline Pluripotent adenoma vs. other cell type & 3.694 & $2.227-5.161$ & $0.011^{\mathrm{b}}$ \\
\hline IHC staining for p16 ( $<7$ vs. $\geq 7 \%$ ) & 4.170 & $2.812-5.522$ & $0.001^{\mathrm{b}}$ \\
\hline IHC staining for p15 (<10 vs. $\geq 10 \%)$ & 2.071 & $0.938-3.204$ & 0.062 \\
\hline IHC staining for $\mathrm{pRb}(\geq 25 \mathrm{vs} .<25 \%)$ & 3.918 & $2.532-5.304$ & $0.004^{\mathrm{b}}$ \\
\hline IHC staining for Cyclin D1 ( $\geq 5$ vs. $<5 \%$ ) & 3.022 & $1.898-4.146$ & $0.013^{\mathrm{b}}$ \\
\hline MIB-1 ( $\geq 2$ vs. $<2 \%$ ) & 2.835 & $1.549-4.121$ & $0.031^{\mathrm{b}}$ \\
\hline Mitotic index ( $\geq 2$ vs. $<2 \%$ ) & 2.673 & $1.235-4.111$ & $0.020^{\mathrm{b}}$ \\
\hline IHC staining for p53 ( $\geq 3$ vs. $<3 \%$ ) & 2.484 & $1.267-3.701$ & $0.029^{\mathrm{b}}$ \\
\hline Knosp classification (II-IV vs. 0-I) & 5.677 & $3.840-7.514$ & $<0.001^{\mathrm{c}}$ \\
\hline Maximal diameter of tumors ${ }^{\mathrm{a}}$ & 2.016 & $0.913-3.119$ & 0.118 \\
\hline $\begin{array}{l}\text { Surgical extent } \\
\text { (gross total resection vs. subtotal resection) }\end{array}$ & 1.253 & $0.704-1.802$ & 0.586 \\
\hline
\end{tabular}

${ }^{a}$ Multivariate analysis was performed for the factors as a form of continuous variable. ${ }^{b} \mathrm{P}<0.05$; ${ }^{\mathrm{c}} \mathrm{P}<0.001$. HR, hazard interval; CI, confidence interval; IHC, immunohistochemical; pRb, retinoblastoma protein; MIB-1, E3 ubiquitin-protein ligase mib1.

A

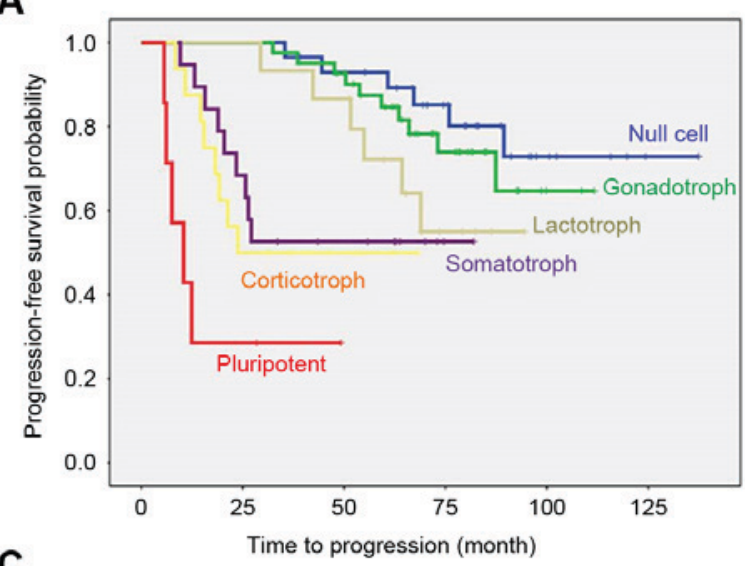

C

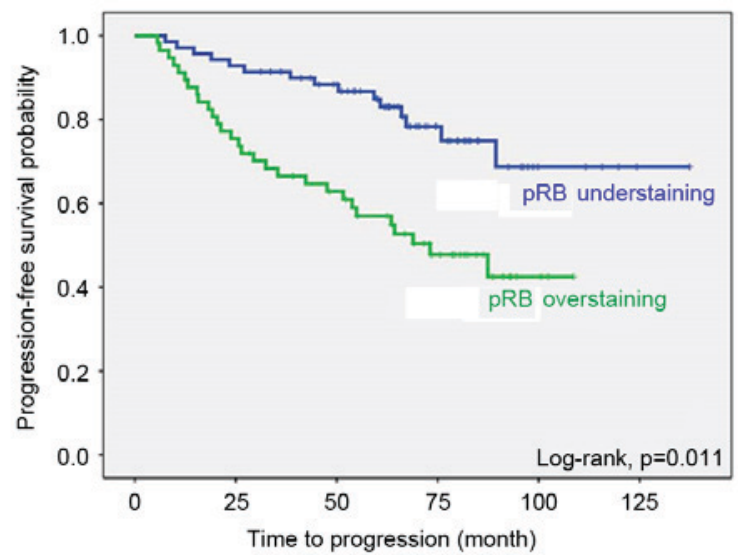

B

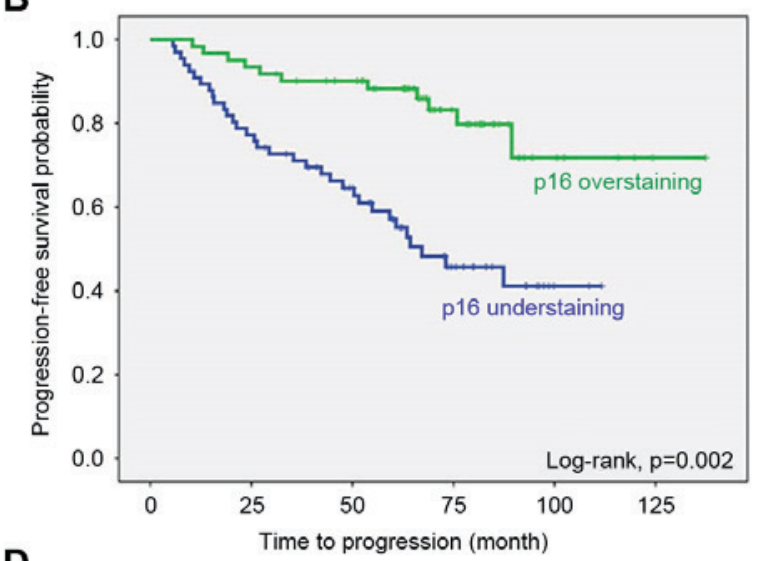

D

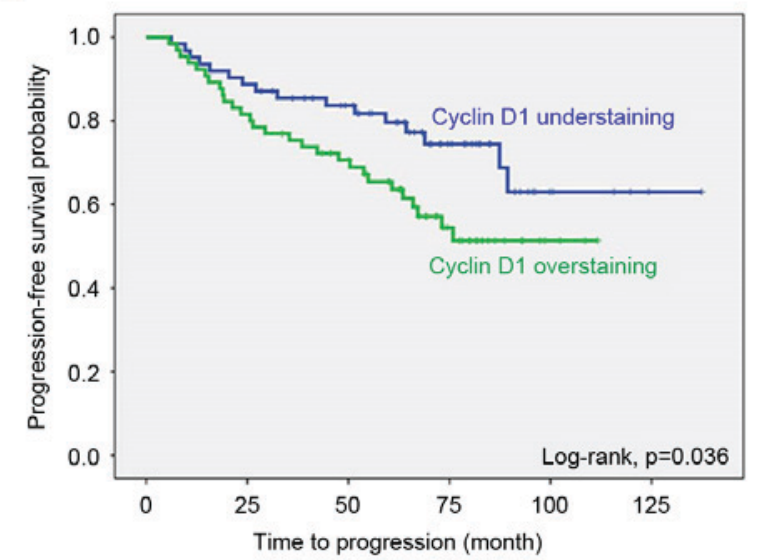

Figure 2. Progression-free survival curve for patients with silent pituitary adenomas. (A) Cells from silent pituitary adenomas. (B) Immunohistochemical understaining $(<7 \%)$ vs. overstaining ( $\geq 7 \%)$ for p16. (C) Immunohistochemical understaining $(<25 \%)$ vs. overstaining $(\geq 25 \%)$ for pRb. (D) Immunohistochemical understaining $(<5 \%)$ vs. overstaining $(\geq 5 \%)$ for cyclin D1. pRb, retinoblastoma protein 
and cyclin D1, were associated with SPA progression. The results were validated using known proliferative markers of MIB-1, mitotic index and p53, which were also significantly associated with SPA progression. Additional studies using systemically developed molecular biology techniques are required to characterize the pathobiological process of SPA progression.

\section{Acknowledgements}

The abstract was presented in the 21st Annual Scientific Meeting and Education Day of the Society for Neuro-Oncology, Scottsdale, Arizona, November 17-20, 2016, and published as abstract MPTH-07 in Nero Oncol 18 (suppl6), 2016. The present study was financially supported by a Samsung Biomedical Research Institute (grant no. SMR-112061). The authors would like to thank Dr Young Min Kim and Dr Mi Ok Sunwoo (Department of Radiology, Samsung Changwon Hospital) for reviewing the neuroradiological images, Ms. Mi-Hyeon Jin (Department of Biostatistics, Samsung Changwon Hospital) for assistance with statistical analysis and Dr Ji Cheol Bae (Department of Endocrinology, Samsung Changwon Hospital) for the endocrine evaluation.

\section{References}

1. Kovacs K, Horvath E and Vidal S: Classification of pituitary adenomas. J Neurooncol 54: 121-127, 2001.

2. Mayson SE and Snyder PJ: Silent pituitary adenomas. Endocrinol Metab Clin North Am 44: 79-87, 2015.

3. Fernandez A, Karavitaki N and Wass JA: Prevalence of pituitary adenomas: A community-based, cross-sectional study in Banbury (Oxfordshire, UK). Clin Endocrinol (Oxf) 72: 377-382, 2010.

4. Raappana A, Koivukangas J, Ebeling T and Pirilä T: Incidence of pituitary adenomas in Northern Finland in 1992-2007. J Clin Endocrinol Metab 95: 4268-4275, 2010.

5. Mayson SE and Snyder PJ: Silent (clinically nonfunctioning) pituitary adenomas. J Neurooncol 117: 429-436, 2014.

6. Syro LV, Rotondo F, Ramirez A, Di Ieva A, Sav MA, Restrepo LM, Serna CA and Kovacs K: Progress in the diagnosis and classification of pituitary adenomas. Front Endocrinol (Lausanne) 6: 97, 2015.

7. Horvath E, Kovacs K, Killinger DW, Smyth HS, Platts ME and Singer W: Silent corticotropic adenomas of the human pituitary gland: A histologic, immunocytologic, and ultrastructural study. Am J Pathol 98: 617-638, 1980.

8. Horvath E, Kovacs K, Smyth HS, Killinger DW, Scheithauer BW, Randall R, Laws ER Jr and Singer W: A novel type of pituitary adenoma: Morphological features and clinical correlations. J Clin Endocrinol Metab 66: 1111-1118, 1988.

9. Klibanski A: Nonsecreting pituitary tumors. Endocrinol Metab Clinic North Am 16: 793-804, 1987.

10. Randall RV, Scheithauer W and Laws ER Jr: Hormone-containing, non-secreting pituitary tumors: Clinically silent monohormonal pituitary adenomas. Trans Am Clin Climatol Assoc 96: 98-103, 1985.
11. Scheithauer BW, Kovacs KT, Laws ER Jr and Randall RV: Pathology of invasive pituitary tumors with special reference to functional classification. J Neurosurg 65: 733-744, 1986.

12. Landolt AM, Shibata T and Kleihues P: Growth rate of human pituitary adenomas. J Neurosurg 67: 803-806, 1987.

13. Knosp E, Kits K and Perneczky A: Proliferation activity in pituitary adenomas: Measurement by monoclonal antibody Ki-67. Neurosurgery 25: 927-930, 1989.

14. Losa M, Franzin A, Mangili F, Terreni MR, Barzaghi R, Veglia F, Mortini P and Giovanelli M: Proliferation index of nonfunctioning pituitary adenomas: Correlations with clinical characteristics and long-term follow-up results. Neurosurgery 47: 1313-1319, 2000

15. Yonezawa K, Tamaki $\mathrm{N}$ and Kokunai T: Clinical features and growth fractions of pituitary adenomas. Surg Neurol 48: 494-500, 1997.

16. Malumbres $\mathrm{M}$ and Barbacid M: To cycle or not to cycle: A critical decision in cancer. Nat Rev Cancer 1: 222-231, 2001.

17. Srivastava V, Patel B, Kumar M, Shukla M and Pandey M: Cyclin D1, retinoblastoma and p16 protein expression in carcinoma of the gallbladder. Asian Pac J Cancer Prev 14: 2711-2715, 2013.

18. Cho HY, Cho SW, Kim SW, Shin CS, Park KS and Kim SY: Silent corticotroph adenomas have unique recurrence characteristics compared with other nonfunctioning pituitary adenomas. Clin Endocrinol (Oxf) 72: 648-653, 2010.

19. Knosp E, Steiner E, Kitz K and Matula C: Pituitary adenomas with invasion of the cavernous sinus space: A magnetic resonance imaging classification compared with surgical findings. Neurosurgery 33: 610-618, 1993.

20. Shim JH, Song YJ, Kim DC, Park MK, Choi SS and Kim KU: Silent adenomas of pituitary gland: It's immunohistochemical features and clinical characteristics. J Korean Neurosurg Soc 40: 330-335, 2006.

21. Eng J: Receiver operating characteristic analysis: A primer. Acad Radiol 12: 909-916, 2005.

22. Chen Y, Wang CD, Su ZP, Chen YX, Cai L, Zhuge QC and Wu ZB: Natural history of postoperative nonfunctioning pituitary adenomas: A systematic review and meta-analysis. Neuroendocrinology 96: 333-342, 2012.

23. Kirsch M, Mörz M, Pinzer T, Schackert HK and Schackert G: Frequent loss of the CDKN2C (p18INK4c) gene product in pituitary adenomas. Genes Chromosomes Cancer 48: 143-154, 2009.

24. Gayed BA, Youssef RF, Bagrodia A, Kapur P, Darwish OM, Krabbe LM, Sagalowsky A, Lotan Y and Margulis V: Prognostic role of cell cycle and proliferative biomarkers in patients with clear cell renal cell carcinoma. J Urol 190: 1662-1667, 2013.

25. Kishimoto I, Mitomi H, Ohkura Y, Kanazawa H, Fukui N and Watanabe M: Abnormal expression of p16(INK4a), cyclin D1, cyclin-dependent kinase 4 and retinoblastoma protein in gastric carcinomas. J Surg Oncol 98: 60-66, 2008.

26. Guo LL, Gao P, Wu YG, Jian WC, Hao CY, Li H and Lin XY: Alteration of cyclin D1 in Chinese patients with breast carcinoma and its correlation with Ki-67, pRb, and p53. Arch Med Res 38: 846-852, 2007.

27. Morgan D, Murray A, Hunt T and Nurse P: The Cell Cycle and Programmed Cell Death. In: Alberts B, Johnson A, Lewis J, Raff M, Roberts K, Walter P (eds): Molecular Biology of the Cell. Garland Science, New York, pp983-1026, 2002.

28. Horvath $\mathrm{E}$ and Kovacs K: The Adenohypophysis. In: Functional Endocrine Pathology. Kovacs K and Asa SL (eds). Blackwell, Boston, MA, pp245-281, 1990. 